\title{
A review on guidelines for hand hygiene in dental practice
}

\author{
Dr. Karkala Sayed Suhaim ${ }^{1}$, Dr. Rahmath Irshana ${ }^{2}$, Dr. Mallika Shetty ${ }^{3}$ \\ ${ }^{I}$ (Assistant Professor, Department of Prosthodontics, Yenepoya Dental College, Yenepoya University, India) \\ ${ }^{2}$ (Tutor, Department of Pedodontics, Yenepoya Dental College, Yenepoya University, India) \\ ${ }_{3}^{3}$ (Reader, Department of Prosthodontics, Yenepoya Dental College, Yenepoya University, India)
}

\begin{abstract}
Wash and care. These two words would probably best summarize the main aspect of hand hygiene in clinical dental practice. Not only are hands the most significant means of germ transmission, they are also the most important dental practice tools. Following the adoption of hand disinfection practice, using chlorinated lime solutions in 1861 by Semmelweis Ignaz, the incidence of hospital acquired diseases has drastically reduced. These primitive guidelines have hence been updated and are constantly reviewed in the light of available newer information. Current evidence indicates that, if recommended infection control procedures are followed, the risks of transmission of infectious diseases during dental treatment is drastically reduced. The implementation of an infection control policy and standard operating procedures requires a thorough knowledge of the risks and the practical measures to be taken using best practice guidelines and recommendations. This article reviews practical measures needed to ensure effective hand hygiene in the dental practice.
\end{abstract}

Keywords: Hand Hygiene Guidelines, Dental practice, Alcohol rub, Occupational hazards

\section{Introduction}

As health care workers we devote our selves to service of humanity with the utmost respect to human life. Contrary to the latter the World Health Organization (WHO) has reported that every day in every country around the globe, in the course of receiving health care, patient are at risk of contracting hospital acquired infections. Patient safety in hospitals continues to remain at risk. Goodman and Solomon ${ }^{1}$ identified and epidemiologically characterized 53 clusters of infections associated with outpatient health care reports, which occurred from 1961 through 1990. Out of the 53 reported data 13 were associated with dental offices. One of the most elementary means of reducing cross infections is by maintaining hand hygiene practices in the dental office. SemmelweisIgnaz ${ }^{2}$ in 1847 reported that hand disinfection could drastically cut the incidence of diseases and proposed the practice of washing with chlorinated lime solutions in 1861.

\section{Normal Microbial Flora On Hands}

The microbial flora of the skin was first described by Price ${ }^{3}$ in 1938, and classified as transient and resident microorganisms. Transient flora, which colonize the superficial layers of the skin, are easier to remove by routine hand washing. Resident flora attached to deeper layers of the skin is more resistant to removal. Montes ${ }^{4}$ established the resident flora consists of microorganisms residing under the superficial cells of the stratum corneum and can also be found on the surface of the skin. Staphylococcus epidermidis is the dominant species ${ }^{5}$. Other resident bacteria include $S$. hominis and other coagulase-negative staphylococci, followed by Corynebacterium ${ }^{6}$. Among fungi, the most common genus of the resident skin flora, when present, is Malassezia spp. ${ }^{7}$

Resident flora has two main protective functions: microbial antagonism and the competition for nutrients in the ecosystem ${ }^{8}$. In general, resident flora is less likely to be associated with infections, but may cause infections in sterile body cavities, the eyes, or on non-intact skin. ${ }^{9}$

\section{Transmission Of Pathogens By Hands}

Transmission of pathogens from one patient to another via the dentist's hands requires five sequential steps.

1. Organisms are present on the patient's skin, or have been shed on to inanimate objects immediately surrounding the patient

2. Organisms must be transferred to the hands of the dentist

3. Organisms must be capable of surviving for at least several minutes on the dentist's hands

4. Hand washing, hand antisepsis or protective barrier used by the dentist must be inadequate, inappropriate or entirely omitted

5. The contaminated hand or hands of the dentist must come into direct contact with another patient or with an inanimate object that will come into direct contact with the patient. 


\subsection{Water and Water Quality}

\section{Factors Effecting Hand Hygiene}

Routine hand washing in health care removes dirt and organic material but is ineffective against hydrophobic substances such as fats and oils often present on soiled hands. Effective hand washing therefore is incomplete with the use of soaps or detergents to dissolve fatty materials. It would be logical to say that the above is a universally accepted protocol, however more often, the following factors are not considered.

Table 1 Summary ofwater quality ${ }^{10}$ classified by Central Pollution Control Board

\begin{tabular}{|l|l|}
\hline Criteria & Standard \\
\hline Total Coliforms Organism & 50 or less MPN/100ml \\
\hline $\mathrm{pH}$ & $6.5-8.5$ \\
\hline Dissolved Oxygen & $6 \mathrm{mg} / \mathrm{l} \mathrm{or} \mathrm{more}$ \\
\hline Biochemical Oxygen Demand 5 days $20^{\circ} \mathrm{C}$ & $2 \mathrm{mg} / 1 \mathrm{or}$ less \\
\hline Total Hardness & $300-600 \mathrm{mg} / \mathrm{l}$ \\
\hline Iron & $0.3-1.0 \mathrm{mg} / 1$ \\
\hline Copper & $0.05 \mathrm{mg} / 1$ \\
\hline Lead & $0.05 \mathrm{mg} / \mathrm{l}$ \\
\hline Chromium & $0.05 \mathrm{mg} / \mathrm{l}$ \\
\hline Dissolved solids & $500-2000 \mathrm{mg} / \mathrm{l}$ \\
\hline
\end{tabular}

4.2 Water temperature

Berardesca et al ${ }^{11}$ compared water temperatures and showed significant association with skin irritation with warmer temperatures. The use of very hot water for hand washing should therefore be avoided as it increases the likelihood of skin damage.

\subsection{Hand drying}

Careful hand drying ensures low level of bacterial transfer. Disposable paper Towels, cloth towels, and warm air dryers are commonly used to dry washed hands. Study ${ }^{11}$ compared four methods of hand drying: cloth towels from a roller; paper towels left on a sink; warm air dryer; and letting hands dry by evaporation; no significant difference in the efficacy of the methods was reported. It was reported that when clean or disposable towels are used, it is important to pat the skin rather than rub it, to avoid cracking. Skin excoriation may lead to bacteria colonizing the skin and possible spread of blood borne viruses as well as other microorganisms ${ }^{12}$.

\subsection{Jewellery}

All hand jewellery including wrist watches must be avoided during operative procedure. Numerous studies have shown that skin underneath rings is more heavily colonized than comparable areas of skin on fingers without rings. Study by Hoffman et $\mathrm{al}^{13}$ found that $40 \%$ of hospital nurses harbored gram-negative bacilli such as Enterobacter cloacae, Klebsiella spp. and Acinetobacter spp. on skin under Jewelry Fingernails and artificial nails

Finger nails must be carefully clipped to avoid damage to the surrounding skin or the lateral nail fold. No correlation has been found in freshly applied nail polish and bacterial load, however clipped nail polish showed significant increase in bacterial growth on fingernails ${ }^{14}$. Numerous studies have documented that subungual areas of the nail and artificial nails harbor high concentrations of bacteria, most frequently coagulasenegative staphylococci, Gram-negative rods (including Pseudomonas spp.), Corynebacteria, and yeasts ${ }^{15}{ }^{16}$. It was also found that even after careful hand washing or surgical scrubs, a substantial numbers of potential pathogens still retained ${ }^{14,15}$

\section{Various Preparations Used For Hand Hygiene}

\subsection{Plain soap (not anti-bacterial)}

Their cleansing activity results in the removal of lipid and adhering dirt, soil, and various organic substances from the hands. Hand washing with plain soap can remove loosely adherent transient flora.

However frequent use can result in a paradoxical increase in bacterial counts on the skin as soaps may be associated with considerable skin irritation and dryness ${ }^{17}$. Occasionally, plain soaps have become contaminated, which may lead to the colonization of the hands with Gram-negative bacilli ${ }^{18}$.

\subsection{Alcohols}

Alcohols are not meant for cleansing when the hands are dirty or visibly contaminated. The antimicrobial activity of alcohols results from their ability to denature proteins ${ }^{19}$. Alcohol solutions containing 60-80\% alcohol are most effective, with higher concentrations being less potent.Regrowth of bacteria on the skin occurs slowly after use of alcohol-based hand antiseptics, presumably because of the sub-lethal effect alcohols have on some of the skin bacteria. ${ }^{20,21}$.Ethanol and Isopropanol are effective in reducing bacterial 
counts when hands are contaminated with small amounts of proteinaceous material,but do not obviate the need for handwashing with water and soap whenever such contamination occurs ${ }^{22}$.Side effects dryness and skin irritation $^{23}$.

\subsection{Chlorhexidine}

The antimicrobial activity of chlorhexidine ${ }^{23}$ appears to be attributable to the attachment, and subsequent disruption of cytoplasmic membranes, resulting in precipitation of cellular contents. Chlorhexidine's immediate antimicrobial activity is slower than that of alcohols. It has good activity against Gram-positive bacteria, somewhat less activity against Gram-negative bacteria and fungi, and minimal activity against mycobacteria. Chlorhexidine is not sporicidal.Chlorhexidine is a cationic molecule, its activity can be reduced by natural soaps, various inorganic anions, non-ionic surfactants, and hand creams ${ }^{24}$ containing anionic emulsifying agents ${ }^{25}$.

\subsection{Chloroxylenol}

The antimicrobial activity of chloroxylenol ${ }^{23}$ is attributable to the inactivation of bacterial enzymes and alteration of cell walls.It has good in vitro activity against Gram-positive organisms and fair activity against Gram-negative bacteria, mycobacteria and some viruses. Chloroxylenol is less active against $P$. aeruginosa, but the addition of ethylenediaminetetraacetic acid (EDTA) increases its activity against Pseudomonas spp. and other pathogens. The antimicrobial activity of chloroxylenol is minimally affected by the presence of organic matter, but is neutralized by nonionic surfactants. Chloroxylenol is absorbed through the skin.

\subsection{Hexachlorophene}

The antimicrobial activity of hexachlorophene ${ }^{27}$ is related to its ability to inactivate essential enzyme systems in microorganisms. Hexachlorophene is bacteriostatic,

With repeated use of 3\% hexachlorophene preparations, the drug is absorbed through the skin. Studies have been reported of neurotoxicity (vacuolar degeneration). The agent is classified by the FDA TFM as not generally recognized as safe and effective for use as an antiseptic handwash.

\subsection{Iodine and Iodophors}

Iodine ${ }^{28}$ molecules rapidly penetrate the cell wall of microorganisms and inactivate cells by forming complexes with amino acids and unsaturated fatty acids, resulting in impaired protein synthesis and alteration of cell membranes.Iodophors are composed of elemental iodine, iodide or triiodide, and a polymer carrier (complexing agent) of high molecular weight. The amount of molecular iodine present (so-called "free" iodine) determines the level of antimicrobial activity of iodophors ${ }^{28}$.

Iodophors cause less skin irritation and fewer allergic reactions than iodine, but more irritant contact dermatitis than other antiseptics commonly used for hand hygiene ${ }^{28}$.

\subsection{Quaternary ammonium compounds (QAC)}

$\mathrm{QACs}^{23}$ are primarily bacteriostatic and fungistatic, although they are microbicidal against some organisms at high concentrations.Antimicrobial efficacy can be severely affected in the presence of hard water

\subsection{Triclosan}

Triclosan ${ }^{29}$ enters bacterial cells and affects the cytoplasmic membrane and synthesis of RNA, fatty acids, and proteins. Recent studies ${ }^{29}$ suggest that this agent's antibacterial activity is attributable in large part to binding to the active site of enoylacyl carrier protein reductase ${ }^{30}$.

\section{Z}

\section{WHO Recommended Hand Rub Formulations}

$\mathrm{WHO}^{31}$ recommended hand rub formulations takes into account cost constraints and microbicidal activity. The following two formulations are recommended for local production with a maximum of 50 liters per lot to ensure safety in production and storage.

Formulation I
a. Ethanol $96 \% \mathrm{v} / \mathrm{v}, 833.3 \mathrm{ml}$
b. $\mathrm{H}_{2} \mathrm{O}_{2} 3 \%, 41.7 \mathrm{ml}$
c. Glycerol $98 \%, 14.5 \mathrm{ml}$

Formulation II
a. Isopropyl alcohol (with a purity of $99.8 \%$ ), $751.5 \mathrm{ml}$
b. $\mathrm{H}_{2} \mathrm{O}_{2} 3 \%, 41.7 \mathrm{ml}$
c. Glycerol $98 \%, 14.5 \mathrm{ml}$ 


\section{Skin Reactions Related To Hand Hygiene}

Contact allergy usually presents as delayed type reactions and less commonly as immediate type skin reaction. Studies have indicated that the most common causes of contact allergies are fragrances, emulsifier and preservatives found in skin lotions ${ }^{32}$.

There are two major types of skin reactions associated with hand hygiene. The first and most common type includes symptoms that can vary from quite mild to debilitating, including dryness, irritation, itching, and even cracking and bleeding. This array of symptoms is referred to as irritant contact dermatitis. The second type of skin reaction, allergic contact dermatitis, is rare and symptoms of allergic contact dermatitis can also range from mild and localized to severe and generalized.

There are three primary strategies for minimizing hand hygiene related irritant contact dermatitis among health care workers ${ }^{33}$

- Selecting less irritating hand hygiene products

- Avoiding certain practices that increase the risk of skin irritation

- Using moisturizing skin care products following hand cleansing.

\section{Hand Washing Guidelines}

1. Periodic water checks should be conducted to ensure optimum water quality and no bacterial colonization in water storage tanks.

2. Remove all hand jewellery including wrist watches. Avoid using artificial nails and nail polish during clinical procedures.

3. Rinse hands under running water. Water at room temperature or warm is ideal. Avoid hot water.

4. Lather with antibacterial soap bar or antibacterial liquid soap using friction. Cover all surfaces of hands and fingers paying particular attention to the thumbs, fingertips, between the fingers, and the backs of the hands, as these are the area most commonly missed. If antibacterial liquid soaps are used the dispensers should be mounted close to the wash basins in easy to reach area.

5. Wash thoroughly under running water. Turn off faucet with wrist/elbow.

6. Dry hands with a paper towels or by using wall mounted automatic air drying machines. Pat skin to dry. Do not rub as this might cause skin to crack. Reusable hand towels should be avoided as it may lead to bacterial colonization.

7. If using antiseptic rub, take an adequate amount and rub on all surfaces for the recommended time. Let the antiseptic dry on its own.

8. Whenever possible pictorial recommendations should be kept over wash basins to endorse and educate effective hand washing.

9. Specialists should be consulted when minimal signs of skin irritation shows and adequate treatment should be taken up.

\section{Remember To Wash Hands}

1. After contact with a patient (e.g., shaking hands with the patients)

2. Before donning sterile surgical or examination gloves

3. After contact with body fluids, mucous membranes, and oral wounds or ulcers

4. After contact with inanimate objects (including medical equipment) in the immediate vicinity of the patient.

5. After removing gloves.

Where hands do not appear to be soiled, an alcohol-based hand rub should be used.

\section{Conclusion}

Hand washing is recognized as a basic measure for preventing any infections. Achieving successful adherence to effective hand hygiene is challenging but not impossible to achieve. Education in hand hygiene should be given priority in medical and dental colleges and dentists need to be educated with clear guidelines and understanding of risks of non-adherence. Evidence based guidelines have always been implemented in various countries. However in India the trend has yet to gain acceptance and implementation. In achieving sustained adherence, selection of strategy requires the presence of a multidisciplinary team which can include infection control and prevention professionals, hospital managers, and pharmacists and efforts should be made to evaluate factors related to hand hygiene products and to conduct clinical pilot projects to test these factors. 


\section{References}

[1] Goodman RA, Solomon SI Transmission of infectious diseases in out-patient health care settings. JAMA1991; 265: 2377-2381

[2] Semmelweis I. Die Aetiologie, der Begriff und die Prophylaxis des Kindbettfiebers [The etiology, concept and prophylaxis of childbed fever]. Pest, Wien und Leipzig, C.A.Hartleben'sVerlag-Expedition, 1861

[3] Price PB. The bacteriology of normal skin: a new quantitative test applied to a study of the bacterial flora and the disinfectant action of mechanical cleansing. Journal of Infectious Diseases. 1938; 63:301-318.

[4] Montes LF, Wilborn WH. Location of bacterial skin flora. British Journal of Dermatology, 1969; 81(Suppl. 1):23-26.

[5] Rayan GM, Flournoy DJ. Microbiologic flora of human fingernails. Journal of Hand Surgery (America), 1987, 12:605-607.

[6] Evans CA et al. Bacterial flora of the normal human skin. Journal of Investigative Dermatology, 1950, 15:305-324.

[7] Hay RJ, Fungi and fungal infections of the skin. In: Noble WC, ed. The skin microflora and microbial skin disease. Cambridge, UK, Cambridge University Press, 199רาว:232-263

[8] Kampf G, Kramer A. Epidemiologic background of hand hygiene and evaluation of the most important agents for scrubs and rubs. Clinical Microbiology Review, 2004, 17:863-893.

[9] Lark RL et al. An outbreak of coagulase-negative staphylococcal surgical-site infections following aortic valve replacement. Infection Control and Hospital Epidemiology, 2001, 22:618-623.

[10] Central Pollution Control Board http://www.cpcb.nic.in/

[11] Berardesca E et al. Effects of water temperature on surfactant-induced skin irritation. Contact Dermatitis, 1995, 32:83-87

[12] Larson EL et al. Changes in bacterial flora associated with skin damage on hands of health care personnel. American Journal of Infection Control, 1998, 26:513-521.

[13] Hoffman PN et al. Micro-organisms isolated from skin under rings worn by hospital staff. BMJ, 1985, 290:206-207.

[14] Baumgardner CA et al. Effects of nail polish on microbial growth of fingernails: dispelling sacred cows. Association of Operating Room Nurses Journal, 1993, 58:84-88.

[15] Hedderwick SA, McNeil SA, Kauffman CA. Pathogenic organisms associated with artificial fingernails worn by healthcare workers. Infection Control and Hospital Epidemiology, 2000, 21:505-509.

[16] McGinley KJ, Larson EL, Leyden JJ. Composition and density of microflora in the subungual space of the hand. Journal of Clinical Microbiology, 1988, 26:950-953.971.

[17] Larson E et al. Physiologic and microbiologic changes in skin related to frequent handwashing. Infection Control, 1986, 7:59-63

[18] Sartor C et al. Nosocomial Serratiamarcescens infections associated with extrinsic contamination of a liquid nonmedicated soap. Infection Control and Hospital Epidemiology, 2000, 21:196-199

[19] Larson EL, Morton HE. Alcohols. In: Block SS, ed.Disinfection, sterilization and preservation, 4th ed. Philadelphia, PA, Lea \&Febiger, 1991:191-203.

[20] Lowbury EJL, Lilly HA, Ayliffe GAJ. Preoperative disinfection of surgeon's hands: use of alcoholic solutions and effects of gloves on skin flora. BMJ, 1974, 4:369-372.

[21] Lilly HA et al. Delayed antimicrobial effects of skin disinfection by alcohol. Journal of Hygiene (London), 1979, 82:497-500.

[22] Parienti JJ et al. Handrubbing with an aqueous alcoholic solution vs. traditional surgical hand.scrubbing and 30.day surgical site infection rates. JAMA, 2002, 288:722-727.

[23] Rotter M. Hand washing and hand disinfection. In: Mayhall CG, ed. Hospital epidemiology and infection control, 2nd ed. Philadelphia, PA, Lippincott Williams \& Wilkins, 1999:1339-1355.

[24] Walsh B, Blakemore PH, Drubu YJ. The effect of hand cream on the antibacterial activity of chlorhexidine gluconate. Journal of Hospital Infection, 1987, 9:30-33.

[25] Larson EL. APIC guideline for handwashing and hand antisepsis in health care settings. American Journal of Infection Control, $1995,23: 251-269$

[26] Larson E et al. Physiologic and microbiologic changes in skin related to frequent handwashing. Infection Control, 1986, 7:59-63

[27] Kimbrough RD. Review of recent evidence of toxic effects of hexachlorophene. Pediatrics, 1973, 51:391-394.

[28] Gottardi W. Iodine and iodine compounds. In: Block SS, ed. Disinfection, sterilization and preservation. Philadelphia, PA, Lea \&Febiger, 1991:152-166.

[29] Jones RD et al. Triclosan: a review of effectiveness and safety in health care settings. American Journal of Infection Control, 2000, 28:184-196.

[30] Ward WH, Holdgate GA, Rowsell S. Kinetic and structural characteristics of the inhibition of enoyl (acyl carrier protein) reductase by triclosan. Biochemistry, 1999, 38:12514-12525.

[31] WHO Guidelines on Hand Hygiene in Health Care. World Health Organization 2009

[32] De Groot AC. Contact allergy to cosmetics: causative Ingredients. Contact Dermatitis, 1987, 17:26-34

[33] Bissett L. Skin care: An essential component of hand hygiene and infection control. British Journal of Nursing, $2007,16: 976-981$. 